\title{
John Sinclair (1933-2007). Language Pioneer and Explorer
}

\author{
Mike Scott \\ University of Liverpool
}

John McHardy Sinclair, who died in March 2007 at the age of 73, was an explorer in the land of language who identified much of the basic geography and mapped out numerous trails as far as large amounts of real language are concerned. As a particularly clear thinker, sometimes dauntingly so, and as a theoretician, Sinclair was able to predict which sorts of initiatives were likely to prosper, and which were doomed to fail or lapse into obscurity. He also had the essential, impressive ability to lead and persuade others so as to get the potentially fruitful initiatives under way.

In a sense Sinclair is the father of Corpus Linguistics. His was the initiative which led to the Bank of English and the whole Cobuild lexicographical endeavour at the University of Birmingham where he was professor in the Department of English from 1965 to 2000. Much of his work was done before any more than a handful of people worldwide had seen the potential of collecting large amounts of ordinary text for linguists to study. It may now in the 21st Century seem odd that real, ordinary text was not extensively or routinely studied in the 1960s to 1990s but instead what linguists or teachers intuited as normal sentences, but that was the world almost all of Sinclair's contemporaries operated in and the world which Sinclair did a great deal to change.

What has Sinclair to do, though, with Language Awareness? The most recent volume of his available to me, Trust the Text: Language Corpus and Discourse (there were always numerous irons in the fire with John and I cannot claim to know how far he had heated and shaped them towards some state of potential publication) makes no mention at all in its index of awareness or of language teaching. It is a volume whose frontispiece claims it reflects 'his most important work in the last decade' and indeed covers Sinclair's major interests grouped under three headings: the theoretical principles underlying language, how text (spoken or written) is structured and organised, and the relationship between lexis and grammar. It is full of insights and suggestion-but it does not make much mention of language teaching or of the importance of awareness in processing and learning and teaching of language. Indeed, at the end of the first contribution, 'Trust the Text', he argues that much in language is not available to awareness:

Until we see what the preliminary results are, we should apply only frameworks that are loose and flexible, in order to accommodate the new information that will come from the text. We should expect to encounter unusual phenomena; we should accept that a large part of our linguistic behaviour 
is subliminal, and that therefore we may find a lot of surprises. We should search for models that are especially appropriate to the study of texts and discourse. (2004: 23)

The point here is that Sinclair saw the importance of models of language, of thinking carefully and non-dogmatically about language, relating instances of language to patterns and to models. Not only from the ivory tower in which he operated, but also in a whole set of associated and related activities such as speech therapy, foreign language teaching, first language policy. In this very spirit Sinclair was fundamental in the late 1980s in encouraging and helping to set up meetings of those interested in Language Awareness. ALA itself was founded in 1992 at a meeting at the University of Wales, Bangor, a meeting for which Sinclair was a major promoter. As such I think it is fair to see it as a seed Sinclair sowed and which has matured to international prominence and importance.

It is, however, far too early for us to be able to fully assess the work and the impact of John McHardy Sinclair. Sinclair's ideas throughout his long academic life were always a couple of decades ahead of their time. Many of his ideas were not properly understood when he stated them, in the sense that their implications took the rest of us years to be perceived. We will have to wait while the other seeds he sowed germinate and mature.

\section{References}

Sinclair, J. McH (2004) Trust the Text: Language Corpus and Discourse. London: Routledge. Mona Baker, Gill Francis and Elena Tognini-Bonelli (1993) Text and Technology: in honour of John Sinclair. Amsterdam: John Benjamins. 